\title{
Ameloblastic Fibrosarcoma
}

National Cancer Institute

\section{Source}

National Cancer Institute. Ameloblastic Fibrosarcoma. NCI Thesaurus. Code C4317.

A locally aggressive malignant neoplasm arising from odontogenic tissue. It occurs in the mandible and less often in the maxilla. It is characterized by the presence of a malignant connective tissue component and a benign epithelial component. The frequency of distal metastases is low. 